\title{
Availability of hydro-chemical indicators of river water
}

\author{
Alexander Volchek $^{1}$, Maya Taratenkova ${ }^{1 *}$ \\ ${ }^{1}$ UO BrSTU, Brest, Republic of Belarus
}

\begin{abstract}
The article contains studies to identify the law of distribution of availability for hydrochemical quality indicators such as dissolved oxygen, BOD5, COD, suspended solids, $\mathrm{pH}$ and mineralization. Time series analysis was carried out using data from the Mukhavets River. The revealed law of distribution allows considering the issues of design and ${ }^{1}$ construction of water facilities more reasonably.
\end{abstract}

Keywords: hydro-chemical quality, availability, river water, dissolved oxygen, BOD5, COD, suspended solids, $\mathrm{pH}$, mineralization.

\section{Introduction}

The intensification of anthropogenic impact on water resources requires changes in the regulation and methodological approach in determining quantitative characteristics. The authors in [7] propose a new approach for sustainable water resources management and achieving long-term water security for people and the environment. It consists in the perception of water resources not only as an integral object but also in understanding the functioning of separate components of the system. The hydrochemical regime of river waters is a complex system that cannot be considered without hydrological parameters as evidenced by the following studies [8]. The authors in the article [9] propose to consider the hydrochemical regime of the catchment through the prism of hydrological and climatic parameters. The results of studies $[11,21]$ testify to the correlation of hydrological and hydrochemical characteristics. When studying the dynamics of river water quality indicators such as total alkalinity, electrical conductivity, dissolved oxygen and others seasonal changes were revealed. This has been confirmed in studies [16]. In work [10], the main sources and factors of changes in the quality of surface waters were identified which include geological, climatic and anthropogenic. The influence of the latter factor on the ecological system of the Republic of Belarus is also discussed in [17]. As stated in article [19], the concentration of dissolved substances such as chlorides, sulfates, etc. also increases with an increase in the degree of urbanization. The mechanisms of interaction between surface and ground waters are described in [12]. The analysis was carried out for the main components of natural waters such as cation-anion composition and electrical conductivity. Another important factor in the formation of the hydrochemical regime of surface waters is the type of feeding as evidenced by the results of studies [18].

\footnotetext{
${ }^{*}$ Corresponding author: taratenkava@mail.ru
} 
In most cases, the study of the hydrochemical regime is carried out according to the average concentrations of quality indicators. The use of such hydrochemical parameters does not often make it possible to adequately assess the state of aquatic ecosystems.

When designing water facilities, building and road structures, the criterion of the availability of hydrological quantities is widely used. This indicator reflects the probability of exceeding the characteristic among its possible values. Most often, it is required to determine the hydrological characteristics of a given supply which is easily solved if the distribution law of this quantity is known. However, in practice, the distribution law is often not known. As for the determination of the availability of hydrochemical values, then mention in the literature, does not occur. Therefore, the study of this issue is of practical interest for engineering calculations in water management design.

Literature sources mention the distribution of errors in the data of hydrological and hydrochemical observations while the complexity and multicomponent nature of the error in observing water quality is noted [6]. The law of distribution of probabilities of various indicators of surface water quality is discussed in works $[13,14]$. The derivation of the statistical distribution is carried out through the balance equation for impurity and water at the water intake. The fact of seasonal variations in surface water quality indicators was also established. The article [15] discusses a number of statistical methods that can be used to describe the dynamics of hydrochemical indicators which indicates the widespread use of statistical approaches in hydrochemistry.

The purpose of this work is to establish the distribution law for the availability of hydrochemical indicators.

\section{Method}

Data of the State Water Cadastre (SWC) of the Republic of Belarus were used in the course of the research in the period from 2010 to 2019. The starting material used for the time series on the Mukhavets River in the alignment above the city of Brest according to the following hydrochemical parameters: BOD5, suspended solids, total mineralization, COD, dissolved oxygen.

Empirical security was determined by the formula:

$$
\mathrm{p}=\frac{\mathrm{m}}{(\mathrm{n}+1)} \cdot 100 \%
$$

where $\mathrm{m}$ - is the ordinal number $x$ in the ranked row; $\mathrm{n}-$ is the length of the row.

Based on the above hydrochemical indicators, empirical supply curves were constructed, according to which the law of supply distribution was selected. The empirical law of distribution of the availability of hydrochemical parameters was carried out for a normal distribution according to the criterion of consent $\chi^{2}$.

The Mukhavets River is a typical Polesye river experiencing anthropogenic pressure from the urbanized territory. The hydrochemical regime of the river was investigated earlier in our work [1] and regularities were found between such parameters as total mineralization and specific conductivity from discharge. According to the results of the study [2,3], it was revealed that the probability density distribution of some water quality indicators obey the two-parameter lognormal law. The synchronicity of the distribution of hydrochemical parameters on the Mukhavets River at sections $1.7 \mathrm{~km}$ below Kobrin and $0.8 \mathrm{~km}$ above Brest was studied in work [4]. 


\section{Results and their discussion}

A hypothesis is put forward in this paper that a random variable which is characterized by a certain distribution law can be a mathematical model for describing the dynamics of hydrochemical processes. This approach has found wide application in hydrology, climatology and other natural sciences. There is no information in the literature on the application of these methods for hydrochemical parameters.

As mentioned above, the random variable ( $\mathrm{x}$ ) is characterized by a distribution law. Analytically, the law is expressed by the distribution function which is described as a parametric expression. With such a record for each value of the random variable, the corresponding value of the distribution function is uniquely determined by the parameters of the analytical expression [5].

When determining the law of distribution of hydrochemical quantities the choice of the type of distribution function should be made taking into account the range of variation of its argument. Changes in the value of hydrochemical parameters usually exceed zero and are theoretically not limited by the upper limit.

When considering the distribution of some hydrochemical parameters (Fig. 1) a certain asymmetry is observed which justifies the assumption of a lognormal distribution.

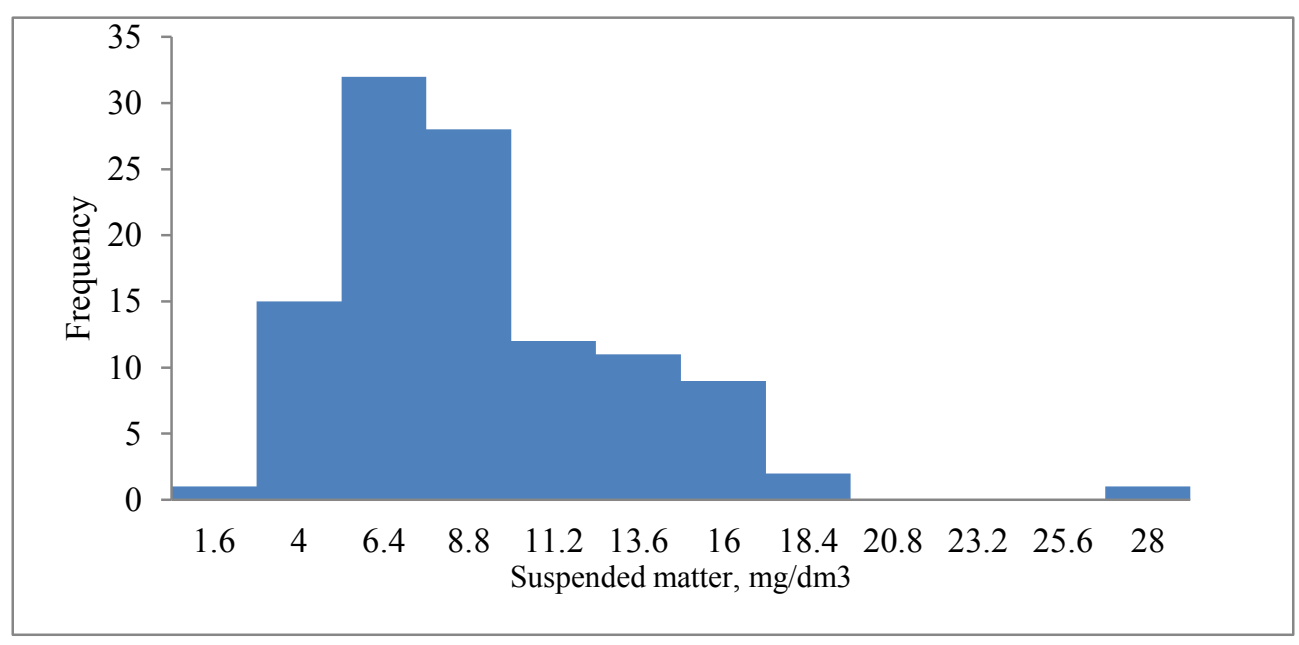

Fig. 1. Histogram of the distribution of suspended solids

Lognormal distribution assumes that the logarithm of the random variable $(z=\ln x)$ is distributed according to the normal law. The cumulative distribution function in this case has the form:

$$
\begin{aligned}
& F(x)=\left\{\begin{array}{c}
0, x \leq 0 \\
F(u)=\frac{1}{\sqrt{2 \pi}} \int_{-\infty}^{u} \exp \frac{-s^{2}}{2} d s, x>0
\end{array}\right. \\
& u=\frac{\left.c z-m_{z}\right)}{\sigma_{z}}
\end{aligned}
$$


where $\mathrm{s}-$ is an integrated variable;

$\mathrm{mZ}$ - mathematical expectation of a random variable $\mathrm{Z}$;

$\sigma \mathrm{Z}-$ is the standard deviation of the random variable $\mathrm{Z}$;

Differentiating expression (2), we obtain the probability density function of the lognormal distribution:

$$
f(x)=\left\{\begin{array}{c}
0, x \leq 0 \\
\frac{1}{\sigma_{2} x} f(u)=\frac{1}{\sigma_{2} x \sqrt{2 \pi}} \exp \left(\frac{-u^{2}}{2}\right), x>0
\end{array}\right.
$$

From expressions (2) and (3) it can be seen that the distribution law depends on two parameters: the mathematical expectation and the standard deviation of a random variable.

The variance, standard deviation and mathematical expectation of a normal distribution of a random variable and a lognormal distribution are related by the following relations [5]:

$$
\begin{gathered}
D_{z}=\sigma_{z}^{2}=\ln \left(\frac{\sigma_{x}^{2}}{m_{x}^{2}}+1\right) \\
m_{z}=\ln \left(m_{x}\right)-\frac{\sigma_{z}^{2}}{2}
\end{gathered}
$$

The series of observations of hydrochemical parameters are, as a rule, of limited length which does not allow determining the values of the maximum or higher supply. An analytical distribution curve was constructed to solve this problem, the curve logically determines the value of the parameter of any security. Distribution curves of security are constructed for such parameters as $\mathrm{BOD}_{5}$, suspended solids, dissolved oxygen, $\mathrm{COD}$, total mineralization. As an example (Figs. 2 and 3), distribution curves for the parameters suspended matter and COD are shown.

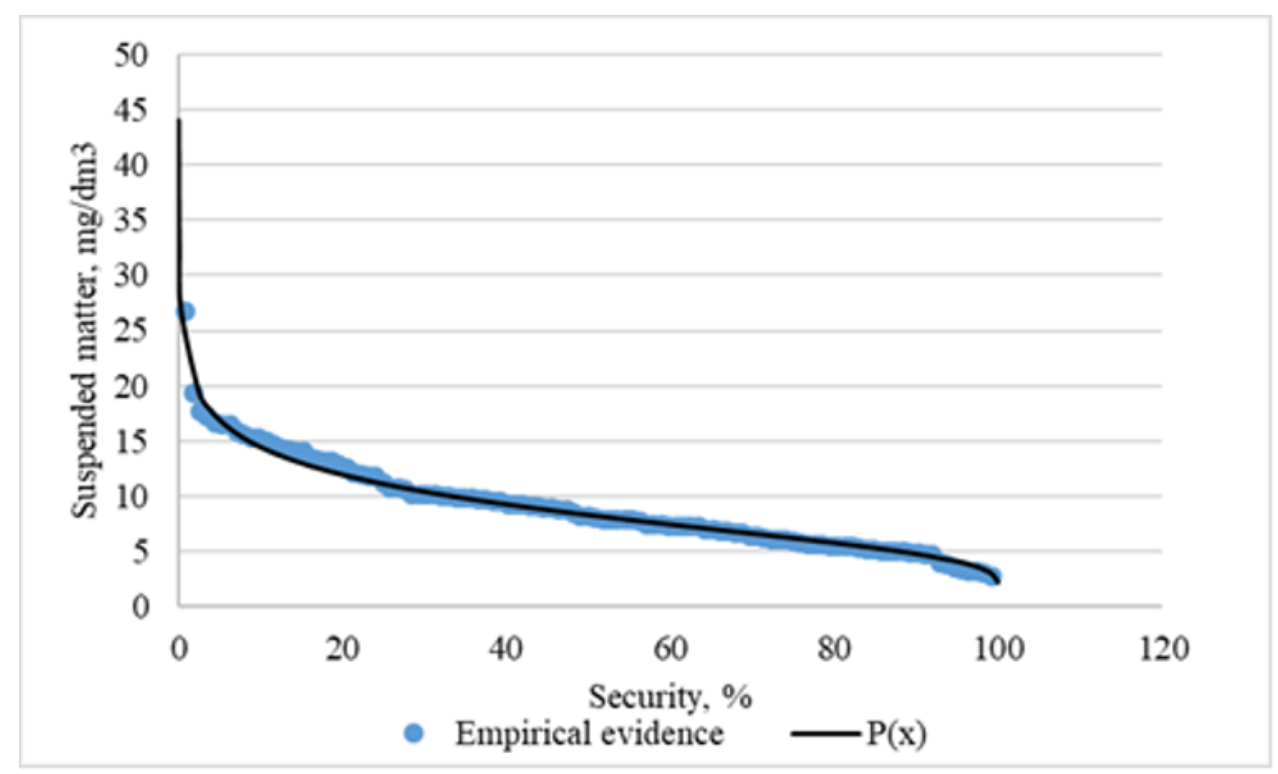

Fig. 2. Schedule of suspended solids supply 


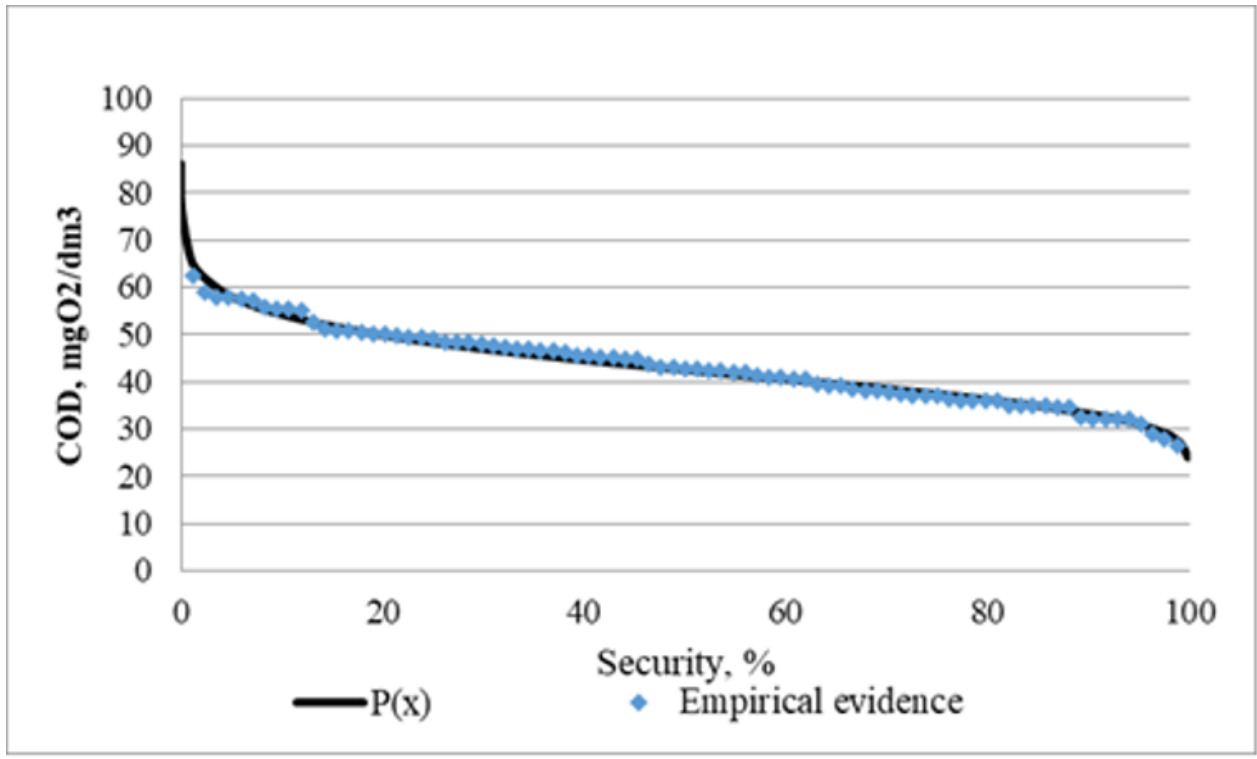

Fig. 3. Schedule of COD supply

Table 1 shows the probability density equation for the distribution of hydrochemical parameters as well as the parameters of the lognormal distribution.

Table 1. Parameters of the lognormal distribution

\begin{tabular}{|l|c|l|}
\hline Indicator & $\begin{array}{l}\text { Density equation of } \\
\text { probabilities of a lognormal distribution }\end{array}$ & $\begin{array}{l}\text { Lognormal distribution } \\
\text { parameters }\end{array}$ \\
\hline BOD 5 & $f(x)=\frac{1}{0,73} \exp \left(-\frac{(\ln x-0,29)^{2}}{0,87}\right)$ & $\begin{array}{l}\mathrm{m}_{\mathrm{z}}=0,29 \\
\sigma_{\mathrm{z}}=0,66\end{array}$ \\
\hline Suspended matters & $f(x)=\frac{1}{1,12} \exp \left(-\frac{(\ln x-2,10)^{2}}{0,41}\right)$ & $\begin{array}{l}\mathrm{m}_{\mathrm{z}}=2,10 \\
\sigma_{\mathrm{z}}=0,45\end{array}$ \\
\hline Mineralization & $f(x)=\frac{1}{0,28} \exp \left(-\frac{(\ln x-5,82)^{2}}{0,02}\right)$ & $\begin{array}{l}\mathrm{m}_{\mathrm{z}}=5,82 \\
\sigma_{\mathrm{z}}=0,11\end{array}$ \\
\hline Dissolved oxygen & $f(x)=\frac{1}{0,55} \exp \left(-\frac{(\ln x-2,14)^{2}}{0,10}\right)$ & $\begin{array}{l}\mathrm{m}_{\mathrm{z}}=2.14 \\
\sigma_{\mathrm{z}}=0,22\end{array}$ \\
\hline $\mathrm{pH}$ & $f(x)=\frac{1}{0,06} \exp \left(-\frac{(\ln x-2,04)^{2}}{0,01}\right)$ & $\begin{array}{l}\mathrm{m}_{\mathrm{z}}=2.04 \\
\sigma_{\mathrm{z}}=0,03\end{array}$ \\
\hline $\mathrm{COD}$ & $f(x)=\frac{1}{0,37} \exp \left(-\frac{(\ln x-3,75)^{2}}{0,06}\right)$ & $\mathrm{m}_{\mathrm{z}}=3,75$ \\
$\sigma_{\mathrm{z}}=0,18$
\end{tabular}

\section{Conclusion}

As a result of studying the time series of quality indicators of the Mukhavets River, it was revealed that the distribution of the availability of hydrochemical quantities, such as $\mathrm{BOD}_{5}$, suspended solids, dissolved oxygen, COD, total mineralization and calcium-ion obey the lognormal distribution law. This makes it possible to determine these parameters with a given security. What can help in water facilities construction. The law of distribution of the availability of the hydrochemical indicator makes it possible to design water treatment facilities with the required degree of reliability and validity. 


\section{References}

1. A.A. Volchek, M.A. Taratenkova, Mat. of the intern. conf. ded. to the 145th anniv. of UE "Minskvodokanal" in two parts, 32-36, (2019).

2. A.A. Volchek, M.A. Taratenkova, Coll. of mat. of the IV Inter. scientific-practical conf., timed to the 1000th anniversary of the city of Brest "Actual problems of geosciences research of transboundary regions" in two parts, 6-10, (2019).

3. A.A. Volchek, M.A. Taratenkova, Coll. of mat. of the regional scientific and practical conf., timed to the 50th anniversary of the Department of Water Supply, Wastewater Disposal and Protection of Water Resources "Advanced Methods of Natural and Waste Water Treatment", 18-23, (2019).

4. A.A. Volchek, M.A. Taratenkova, Agrar. Land., their stability and development features: collection of scientific papers based on materials from Mezhdunar. scientific. eco. conf., 401-404, (2020).

5. A.V. Sikan, Methods of statistical processing of hydrometeorological information, 279 p., (2007).

6. H. Mcmillan, J. Freer, T. Krueger, Hydrological Processes 4078-4111. (2012).

7. Th. Wagener, M .Sivapalan, P.A Troch, B.L. McGlynn, C. J. Harman, H.V. Gupta,

P. Kumar, P.S.C. Rao, N.B. Basu, J.S. Wilson. Water Resources Research, 46 (5), 1-10 (2010).

8. A. Hodson, M. Tranter, A. Gurnell, M. Clark, J.O Hagen, 2002, 1-4, 91-114.

9. C. Soulsby, C. Gibbins, A. J.Wade, R. Smart, R. Helliwell, Science of the Total Environment, 1-3, 73-94, (2002).

10. R. Bouza-Deaño, M. Ternero-Rodríguez, A. J. Fernández-Espinosa, Journal of Hydrology, 631 (3-4), 227-239, (2008).

11. A. R.C. Ovalle, C. F. Silva, C. E. Rezende, C. E.N. Gatts, M. S. Suzuki, R. O Figueiredo, Journal of Hydrology, 191-203 (2013).

12. M. R. Guggenmos, C. J. Daughney, B. M. Jackson, U. Morgenstern, Hydrology and Earth System Sciences, 15, 3383-3398, (2011).

13. B.M. Dolgonosov, K.A. Korchagin, Water Resources, 1, 39-48, (2014).

14. B.M. Dolgonosov, K.A. Korchagin, Water Resources, 3, 345-358, (2011).

15. C. E.M. Lloyd, J. E. Freer, A. L. Collins, P. J. Johnes, J. I. Jones, Journal of Hydrology, 514, 297-312, (2014).

16. V.M. Shulkin, N.N. Bogdanova, L.V. Perepelyatnikov Water Resources, volume 36, 4, 428-439, (2009).

17. V.S. Khomich, Nature management, 22, 26-32 (2012).

18. C. Neal, J. Wilkinson, M. Neal, M. Harrow, H. Wickham, L. Hill, C. Morfitt, Hydrology and Earth System Sciences, 1, 583-617, (1997).

19. S. Rose, Journal of Hydrology,341(1-2):42-54, ( 2007).

20. C. Soulsby, C. Gibbins, A. J. Wade, R. Smart, R. Helliwell, Science of the Total Environment, 256 (1-3), 51-63, (2002). 